\title{
A study on male adult' appearance management behavior according to objectified body consciousness
}

\author{
Misook Lee ${ }^{\dagger}$ \\ Dept. of Fashion Design \& Merchandising, Kongju National University, Korea \\ 성인 남성의 객체화 신체의식에 따른 외모관리행동 연구 \\ 이 미 숙 ${ }^{\dagger}$ \\ 공주대학교 의류상품학과
}

\begin{abstract}
The purpose of this study was to investigate male adult' appearance management behavior according to objectified body consciousness. The subjects were 648 male adults aged from 20 to 59 and measuring instruments consisted of objectified body consciousness, appearance management behavior, and subjects' demographics attributions. The data were analyzed by Cronbach's $\alpha$, factor analysis, cluster analysis, multiple response analysis, cross tabs analysis, $\chi^{2}$ test, and $t$-test. The results were as follows. First, 3 dimensions (body shame, body surveillance, and control belief) were emerged on objectified body consciousness, and subjects were divided into 2 groups (objectified group, and non-objectified group) by this variable. Second, male adults were deeply aware of the need of appearance management, and showed the high level of intention to perform appearance management behavior. Third, objectified group showed much more active appearance management behavior than non-objectified group. This results concluded that objectified body consciousness is a very useful variable to understand male adult' appearance management behavior.
\end{abstract}

Keywords: objectified body consciousness(객체화 신체의식), appearance management behavior(외모관리행동), male adult(성인 남성)

\section{Introduction}

21세기 들어서면서 외모지상주의의 영향으로 취 업, 승진, 데이트 등의 다양한 사회생활에서 외모가 유용하고 중요한 경쟁력이라는 사회적 인식이 널
리 확산됨에 따라 외모관리에 대한 관심이 점차 증 가하고 있다. 과거에는 외모의 중요성이 주로 여성 에게만 해당되는 것으로 생각했으나, 현대 사회에 서는 성역할의 변화로 인해 그루밍(grooming)족, 여 미(yummy)족, 꽃중년, 로엘(roel)족 등 외모에 아낌 없이 투자하는 남성을 일컫는 다양한 신조어들이 등

Received 21 July 2014, revised 1 September 2014, accepted 6 October 2014.

${ }^{\dagger}$ Corresponding author (evanms@kongju.ac.kr)

This is an Open Access article distributed under the terms of the Creative Commons Attribution Non-Commercial License (http://creativecommons.org/licenses/by-nc/3.0) which permits unrestricted non-commercial use, distribution, and reproduction in any medium, provided the original work is properly cited. 
장한 것처럼(Spruce men $\cdots$ Yummy tribe'is increasing, 2014), 남성들도 자신의 외모를 향상시키기 위해 많은 관심을 가지고 다양한 외모관리행동을 수행 하고 있다. 더구나 외모는 타고난 것이라는 과거 개념과는 달리, 렛미인(Let美人), 옴므(HOMME) 등 최근 급격히 증가하고 있는 외모관련 매스미디어 프로그램에서 볼 수 있는 것처럼, 외모는 만들어지 고 관리되는 것이라는 관념이 형성되면서 남녀 모 두에게 외모관리에 대한 사회적 요구와 기대가 증 가하고 있다.

시장조사기관인 유로모니터의 자료에 따르면 한 국의 남성 1 인당 스킨케어 소비규모는 세계 1 위인 25 달러 30 센트로, 이는 2 위인 덴마크의 3 배에 이르 는 규모라고 하였고, 명품시장에서도 남성 소비비 중이 $40 \%$ 에 육박하고 있으며, 패션과 외모에 관심 을 쏟는 남성 소비층 덕분에 올해 매출이 $8 \%$ 이상 늘어날 것으로 전망하였다("Rapid growth of male tribe of value consciousness consumption", 2014). 이 와 같이 외모관련 산업에서 남성이 차지하는 시장 규모가 증가하면서 남성 소비시장은 새로운 블루 오션으로 주목 받고 있다. 초기에는 주로 20 30대 의 젊은 층이 주 소비대상이었으나, 이제는 경제력 을 갖춘 40 50대의 중년 남성들도 외모관리에 보 다 적극적인 태도를 보이면서 남성의 외모관리행 동이 전 연령층으로 확산됨에 따라, 남성 소비시장 의 규모는 더욱 빠르게 성장하고 있다("No more uncle", 2013).

그러나 지금까지의 외모관련 연구들은 주로 여 성을 중심으로 수행되어 왔으며, 남성을 대상으로 한 연구는 아직 부족하다. 최근 들어 남성의 외모 관리행동을 조사한 연구들이 많이 이루어지고 있 으나, 대부분이 20 대 초반의 대학생이나 20 30대의 젊은 남성층만을 대상으로 수행되었으며, 새롭게 주 목받고 있는 소비계층인 40 대 이후의 남성을 포함 하여 조사한 연구(Jung \& Lee, 2011; Ku, Lee, \& Choo, 2011; Lee, 2007; Lee, 2012; Park \& Yoo, 2012)는 아직까지 매우 드물다. 따라서 보다 다양 한 연령층을 대상으로 남성의 외모관리행동을 폭 넓게 이해하기 위한 연구가 필요하다. 또한 남성의 외모관리행동을 조사한 연구들을 살펴보면 주로 남성의 외모관리행동을 단편적으로 이해하기 위한
탐색적 연구가 대부분이며, 남성의 외모관리행동에 영향을 미칠 수 있는 보다 다양한 사회심리학적 선 행변인을 조사하고, 이들과의 관계를 살펴본 연구 는 아직까지 부족한 실정이다.

객체화된 신체의식은 객체로서 자신의 신체를 바 라보고 느끼는 심리적 경험을 말하는 것(Mackinley \& Hyde, 1996)으로, 외모관리행동에 영향을 미치는 중요한 변인으로 제시되고 있다. 객체화 신체의식 은 처음에는 여성을 대상으로 개발된 개념이었으 므로 대부분의 선행연구들이 여성을 대상으로 수 행되었으나, 최근 여성뿐만 아니라 남성들도 자신 의 신체를 객체로 인식하고 있음이 밝혀졌다(Morry \& Staska, 2001; Murnen, 2003). Gim, Ryu, and Park (2007)도 남녀 대학생을 대상으로 객체화 신체의식 을 조사한 결과, 신체감시성, 신체수치심, 통제신념 에서 뚜렷한 성차가 존재하는 것으로 나타났으며, 이에 대해 향후 연구가 필요하다고 제안하였다. 그 러나 지금까지의 객체화 신체의식에 대한 선행연 구는 여성을 대상으로 소수의 연구만이 진행되었 을 뿐(An, 2007; Jeon \& Chung, 2011; Jeon \& Yoo, 2011; Kim, 2007), 남성을 대상으로 이루어진 연구 는 거의 찾아보기 어려운 실정이다. 따라서 본 연 구에서는 20 50대의 성인 남성을 대상으로 객체화 신체의식과 외모관리행동을 알아보고, 객체화 신체 의식에 따라 성인 남성의 외모관리행동에 어떠한 차이가 있는지를 파악해 보고자 한다. 이러한 연구 는 외모에 대한 사회문화적 환경이 성인 남성의 외 모관리행동에 미치는 영향을 파악하고, 성인 남성 의 외모관리행동을 보다 구체적으로 이해하는데 도움을 주며, 또한 성인 남성을 대상으로 하는 외 모관련업체들에게는 남성시장을 세분화하고, 세분 시장의 욕구를 충족시킬 수 있는 상품기획 및 마케 팅전략을 수립하기 위한 유용한 정보를 제공한다 는데 연구의 의의가 있다.

\section{Review of Literature}

\section{Objectified body consciousness}

객체화 신체의식이란 자신을 전인견적 주체의 일부로 보지 않고, 관찰하고 이용할 객체로 간주하 는 것을 의미한다. 객체화 이론에 따르면, 외모를 
중시하는 사회적 환경의 영향은 자연스럽게 자신 의 외모에 대한 습관적인 감시와 통제를 통해 자신 의 신체를 타인에 의해 평가되는 객체로 인식하는 자기대상화를 유발하며(Fredrickson \& Roberts, 1997), 사회적으로 제시된 이상적인 신체기준을 내면화하 고, 이 기준과 비교하여 자신의 신체를 지속적으로 감시하고 바라봄으로써 자기가치와 정체성의 근원 을 신체적 외모에 두려는 경향을 보이고 외모에 치 중하게 된다고 주장한다(McConnell, 2001). Mackinley and Hyde(1996)는 객체화 신체의식을 자신의 신체 를 객체화하여 타인의 시선에서 바라보는 신체감 시, 문화적 신체표준의 내면화에 의한 신체수치심, 개인의 외모를 변형시킬 수 있다는 통제신념의 3요 인으로 분류하여 객체화 신체의식 측정도구를 개 발하였다. Calogero, Davis, and Thompson(2005)은 대중매체가 보여주는 이상적 외모에 대한 내면화 가 자기 객체화에 영향을 주어 사회에서 이상적이 라고 제시되는 외모를 추구하게 된다고 하였으며, 외부로부터 형성된 미적기준에 도달하지 못했을 때 에는 신체에 대한 수치심과 부정적 감정을 유발하 여 자신의 신체를 향상시키기 위해 다양한 외모관 리행동을 수행한다고 함으로써 객체화 신체의식이 외모관리행동에 영향을 미치는 중요한 변인임을 시 사하였다(Kretchmar, 2001; Noll \& Fredrickson, 1998). Gim et al.(2007)도 한국판 객체화 신체의식 척도 (K-OBCS)를 개발하여 조사한 결과, 객체화 신체의 식은 외모관리행동의 경험과 의도를 예측하는데 중요한 변인임을 밝혔다.

객체화 신체의식에 대한 선행연구들은 주로 여 성(An, 2007; Gim, Park, \& Timothy, 2009; Jeon \& Chung, 2011; Jeon \& Yoo, 2011)을 중심으로 이루 어졌으며, 남녀 청소년(Lim, 2010)이나 대학생 $(\mathrm{Gim}$ et al., 2007; Kim, 2007)을 대상으로 이루어진 연구 가 일부 존재할 뿐, 아직까지 남성만을 대상으로 수행된 경우는 찾아보기 어렵다. 객체화 신체의식 에 관한 선행연구 결과들을 살펴보면, 성인 여성은 신체수치심이 크고 신체감시를 많이 하며 외모통 제신념도 높았으며, 객체화된 신체의식이 높을수록 외모관리의 경험과 수행의도가 높은 것으로 나타 났다(An, 2007; Jeon \& Yoo, 2011; Kim, 2007). 성 별에 따른 차이를 살펴보면 여성이 남성보다 전반
적인 객체화 신체의식이 높았으나, 객체화 신체의 식 하위차원에서 신체감시성과 신체수치심은 여성 이 남성보다 높은 반면, 외모통제신념은 남성이 여 성보다 높은 것으로 제시되었다(Lim, 2010). 또한 객체화 신체의식과 외모관리행동과의 관계를 살펴 보면, 신체수치심과 신체감시성이 높을수록 자신의 신체를 부정적으로 평가함으로써 외모관리행동을 더 많이 수행하는 것으로 나타났는데, 이러한 경향 은 여성이 남성보다 더 강하게 나타났다(Kim, 2007; $\mathrm{Lim}, 2010)$. 한편, 외모통제신념과 외모관리행동과 의 관계는 성별에 따라 차이가 있어 남학생의 경우 는 통제신념이 낮을수록 외모관리행동을 더 많이 수행한 반면, 여학생은 통제신념이 외모관리행동에 유의한 영향을 미치지 않았다(Lim, 2010).

\section{Male adults' appearance management behavior}

외모관리란 개인이 타인과의 상호작용을 통해 자신의 역할을 연기하면서 자신의 개성을 표현해 가는 과정을 의미한다(Kaiser, 1990). 개인은 자신의 모습을 다른 사람에게 제시하는 과정에서 사회문 화적으로 제시된 이상적인 미적 기준과 자신을 비 교하고 평가하며, 그 차이를 극복하기 위해 의복연 출, 체형관리, 피부관리, 메이크업, 헤어관리, 성형 수술 등의 다양한 외모관리행동을 수행한다.

남성의 외모관리행동에 대한 선행연구들 결과를 살펴보면 다음과 같다. 먼저 성인 남성은 다양한 외모관리행동 중에서 체형관리를 가장 중요하게 고려하는 것으로 보여지나, 연령에 따라 실제 수행 하는 외모관리행동에는 차이가 있어 20 30대 남성 들은 운동, 식이요법 등의 체형관리를 많이 하는 반면(Kim \& Park, 2010; Woo, 2005), 대학생들은 체 형관리보다는 손쉽게 외모를 향상시킬 수 있는 의 복과 헤어관리행동을 더 많이 하는 것으로 나타났 으며(Park \& Chung, 2011; Park \& Park, 2008; Woo $\&$ Choi, 2011), 성형에 대해서는 아직 보수적인 태 도를 지니고 있는 것으로 제시되었다(Ku et al., 2010). 남성의 외모관리 동기로는 자기만족이 가장 중요 한 이유로 제시되었으며(Jung \& Lee, 2011; Woo, 2005), 그 외에 남들의 시선, 사회적 권력추구, 개성 표현, 동조성, 자기개발 동기 등이 주요 동기로 제 시되었다(Ha, 2009; Ryou \& Kim, 2008; Sung, Park, 
Choi, Kim, \& Lee, 2008). 남성들은 오프라인보다 는 익명성이 보장되는 인터넷을 외모관리를 위해 사용하는 정보원으로 중요시하였으며, 연령이 젊을 수록 인터넷을 중시하는 반면, 연령이 증가할수록 TV를 중시하는 경향을 보였다(Kim, 2011; Ku et al., 2010).

남성의 객체화 신체의식과 외모관리행동에 대한 선행연구 결과를 정리해보면 다음과 같다. 객체화 신체의식은 외모에 대한 사회문화적 현상을 이해 하기 위한 변인으로 비교적 최근에 등장한 개념으 로서, 주로 여성을 위주로 소수의 연구만이 진행되 어 아직까지 남성의 객체화 신체의식을 구체적으 로 파악하고, 외모관련행동과의 관계를 밝힌 연구 는 찾아보기 어렵다. 선행연구를 살펴보면 객체화 신체의식과 외모관리행동, 그리고 이 두 변인 간의 관계는 뚜렷한 성차가 존재하는 것으로 예측되므 로 남성을 대상으로 한 체계적인 연구를 진행할 필 요가 있다. 또한 최근 남성의 외모관리에 대한 관 심과 수요가 증가함에 따라 남성의 외모관리행동 에 대한 연구가 활발히 진행되고 있다. 그러나 주 로 20 30대의 외모관리 실태와 태도에 대한 연구 가 대부분이며 다양한 연령층에 걸쳐 외모관련 구 매행동을 포함하여 조사한 연구는 아직까지 매우 부족한 실정이다. 따라서 본 연구에서는 20 50대의 폭넓은 연령층의 성인 남성을 대상으로 객체화 신 체의식을 조사함으로써 외모에 대한 사회문화적 환경이 성인 남성의 외모관리행동에 어떠한 영향 을 미치지는 파악하고, 외모관리행동을 외모관리동 기, 정보원 활용, 관리비용, 외모관리경험, 외모관 리의 필요성과 수행의도 등 구매행동을 포함한 보 다 다양한 외모관리측면을 중심으로 객체화 신체의 식과 외모관련행동과의 관계를 파악해보고자 한다.

\section{Research Methods}

\section{Research questions}

본 연구에서는 20 50대의 성인 남성을 대상으로 객체화 신체의식과 외모관리행동을 알아보고, 객체 화 신체의식에 따라 성인 남성의 외모관리행동에 어떠한 차이가 있는지를 파악하기 위해 실시되었 으며, 구체적인 연구문제는 다음과 같다.
연구문제 1. 성인 남성의 객체화 신체의식 하위 차원을 규명한다.

연구문제 2. 객체화 신체의식 하위 요인을 기준 으로 남성 소비자를 유형화하고, 유형화된 집단 간 인구통계학적 특성에 유의한 차이가 있는 지를 규 명한다.

연구문제 3. 성인 남성의 외모관리행동을 여섯 측면(외모관리 동기, 정보원 활용, 외모관리 비용, 외모관리 경험, 외모관리의 필요성과 수행의도)에 서 평가한다.

연구문제 4. 객체화 신체의식 하위 요인에 따라 유형화된 남성 소비자 집단 간 외모관리행동에 유 의한 차이가 있는 지를 규명한다.

\section{Measuring instruments}

연구방법은 설문조사방법으로, 설문지는 크게 객 체화 신체의식 측정문항, 외모관리행동 측정문항, 피험자의 인구통계학적 특성에 대한 문항의 3 부분 으로 구성되었다. 객체화 신체의식 측정문항은 $\mathrm{Gim}$ et al.(2007)에 의해 개발된 한국판 객체화 신체의식 척도(K-OBCS)를 토대로 총 15 문항으로 구성되었 고, 신뢰도는 .61 .81이었으며, 5점의 Likert형 척도 (1: 전혀 그렇지 않다, 3 : 보통이다, 5: 매우 그렇다) 로 제시되었다. 외모관리행동에 대한 측정문항은 남성의 외모관리행동에 대한 선행연구 $(\mathrm{Ku}$ et al., 2011; Woo \& Choi, 2011)를 토대로 외모관리 동기, 외모관리정보원, 외모관리비용, 외모관리경험, 외 모관리의 필요성과 수행의도에 대한 총 13 문항으 로 구성되었으며, 외모관리의 필요성과 수행의도는 5점의 Likert형 척도로, 그 외의 문항은 선다형식 (multiple choice)으로 제시되었다. 한편, 피험자의 인구통계학적 특성에 대한 문항으로는 피험자의 연령, 학력, 결혼 여부, 직업, 월 소득, 한 달 용돈에 대한 6 문항이 선다형식으로 제시되었다.

본 연구를 위한 설문지는 의류학 분야의 박사학 위를 지닌 5 명의 전문가와의 토의를 통해 문항의 내용 타당성을 조사하였으며, 대전지역에 거주하 는 20 50대의 남성 60 명을 대상으로 예비조사를 실시하여 객체화 신체의식 척도의 신뢰도를 조사 하고, 각 설문문항의 내용에 대한 이해도를 확인하 였다. 


\section{Research subjects}

연구대상은 20 59세의 성인 남성으로, 본 연구 를 위한 피험자는 서울, 경기지역과 대전, 충남지역 에 거주하는 남성 총 660 명을 편의표집방법을 통해 선정하였으며, 피험자의 인구통계학적 특성은 〈Table $1\rangle$ 과 같다.

\section{Data collection and analysis}

본 연구를 위한 설문조사는 2013년 8월 16일 23 일에 실시되었으며, 회수된 660 부 중에서 불성실하 게 응답한 설문지를 제외하고, 총 648 부가 최종 자 료분석에 사용되었다. 구체적인 자료분석방법으로

$\langle$ Table 1〉 Subjects' demographic characteristics

\begin{tabular}{|c|c|c|}
\hline \multicolumn{2}{|r|}{ Variables } & $\mathrm{N}(\%)$ \\
\hline \multirow{4}{*}{$\begin{array}{l}\text { Age } \\
\text { group }\end{array}$} & 20 29 years old & $158(24.4)$ \\
\hline & 30 39 years old & $161(24.8)$ \\
\hline & 40 49 years old & $166(25.6)$ \\
\hline & $50 \sim 59$ years old & $163(25.2)$ \\
\hline \multirow{3}{*}{$\begin{array}{c}\text { Education } \\
\text { level }\end{array}$} & Less high school education & $102(15.8)$ \\
\hline & College graduates & $472(72.8)$ \\
\hline & Grad school graduates & $74(11.4)$ \\
\hline \multirow{7}{*}{$\begin{array}{c}\text { Type of } \\
\text { occupation }\end{array}$} & Students & $98(15.1)$ \\
\hline & Office work & $264(40.7)$ \\
\hline & Specialized work & $34(5.2)$ \\
\hline & Management/administrative work & $64(9.9)$ \\
\hline & Sales/service work & $77(11.9)$ \\
\hline & Production/technical work & $69(10.6)$ \\
\hline & Inoccupation & $20(3.1)$ \\
\hline \multirow{3}{*}{$\begin{array}{c}\text { Marital } \\
\text { status }\end{array}$} & Not married & $277(42.7)$ \\
\hline & Married & $356(54.9)$ \\
\hline & Others(divorce, bereavement) & $15(2.3)$ \\
\hline \multirow{4}{*}{$\begin{array}{c}\text { Household } \\
\text { income }\end{array}$} & Less than $2,000,000$ won & $137(21.1)$ \\
\hline & $2,000,000$ less than $4,000,000$ won & $286(44.1)$ \\
\hline & $4,000,000$ - less than $6,000,000$ won & $138(21.3)$ \\
\hline & Over $6,000,000$ won & $87(13.4)$ \\
\hline \multirow{4}{*}{$\begin{array}{l}\text { Pocket } \\
\text { mony } \\
\text { per a } \\
\text { month }\end{array}$} & Less than 200,000 won & $142(21.9)$ \\
\hline & 200,000 less than 400,000 won & $286(44.1)$ \\
\hline & 400,000 less than 600,000 won & $90(13.9)$ \\
\hline & Over 600,000 won & $130(20.1)$ \\
\hline
\end{tabular}

는 SPSS 통계프로그램(Ver. 20.0)을 사용하여 기술 통계, 요인분석, 신뢰도분석, 군집분석, 다중응답분 석, 교차분석, $\chi^{2}$ 검증, $t$-test를 실시하였다.

\section{Result and Discussion}

\section{Objectified body consciousness}

성인 남성의 객체화 신체의식에 대한 구성차원 을 알아보기 위해 주성분분석과 Varimax 회전방법 을 사용하여 요인분석을 실시한 결과, 3 개의 요인 이 추출되었다. 첫 번째 요인은 자신이 생각하는 이상적인 모습이 아닐 때 수치심을 느끼는 내용으 로 구성되어 '신체수치심'으로 명명하였고, 두 번째 요인은 자신의 신체보다는 외모에 집중하고 타인 에게 자신의 모습이 어떻게 보여지는가에 대한 내 용으로 구성되어 '신체감시성'으로 명명하였으며, 세 번째 요인은 외모는 유전보다는 자신의 노력에 의해 변화 또는 향상될 수 있다고 믿는 내용으로 구성되어 '통제신념'으로 명명하였다.

성인 남성의 객체화 신체의식 수준을 알아보기 위해 각 요인에 해당하는 문항에 대한 평균점수를 도출하였다. 점수의 해석은 점수가 높을수록 신체 수치심, 신체감시성, 통제신념이 높은 것을 의미한 다. 각 요인의 평균점수를 살펴보면, 신체수치심이 3.08 , 신체감시성이 3.06 , 통제신념이 3.72 로 나타났 는데, 객체화 신체의식이 5점의 Likert형 척도로 조 사된 점을 고려해볼 때, 성인 남성의 신체수치심과 감시성은 중간 수준인 반면, 통제신념은 높은 수준 임을 알 수 있었다.

남자의 객체화 신체의식을 조사한 선행연구(Gim et al., 2007; Kim, 2007)는 요인별 점수를 제시하고 있지 않아 직접적인 결과의 비교가 어려웠다. 한편, 남자 고등학생의 객체화 신체의식을 본 연구와 동 일하게 5점 Likert형 척도로 조사한 $\operatorname{Lim}(2010)$ 의 연 구에서는 신체감시성이 3.12 , 신체수치심이 2.29 , 통제신념이 3.56으로 나타났는데, 이를 본 연구결 과와 비교해보면 신체감시성과 통제신념은 본 연 구결과와 유사한 맥락으로 보여지나, 신체수치심에 서는 차이가 있어 남자 고등학생은 중간보다 상당 히 낮은 수준(2.29)으로 나타난 반면, 성인 남성은 신체수치심이 중간 수준(3.08)으로 제시되었다. 이 
$\langle$ Table 2〉 Dimensions of objectified body consciousness

\begin{tabular}{|c|c|c|c|c|c|}
\hline Factor & Questions & $\begin{array}{l}\text { Factor } \\
\text { loading }\end{array}$ & Variance & $\begin{array}{c}\text { Cronbach' } \\
\alpha\end{array}$ & Mean \\
\hline \multirow{5}{*}{$\begin{array}{c}\text { Body } \\
\text { shame }\end{array}$} & I feel shamed of myself when I haven't made the effort to look my best. & .82 & \multirow{5}{*}{$\begin{array}{c}24.56 \\
(24.56)\end{array}$} & \multirow{5}{*}{.81} & \multirow{5}{*}{3.08} \\
\hline & I feel like I must be a bad person when I don't look as good as I could. & .77 & & & \\
\hline & When I'm not the size I think I should be, I feel ashamed. & .76 & & & \\
\hline & When I can't control my weight, I feel like something must be wrong with me. & .72 & & & \\
\hline & During a day, I think about how I look many tines. & .64 & & & \\
\hline \multirow{4}{*}{$\begin{array}{c}\text { Body } \\
\text { surveil- } \\
\text { lance }\end{array}$} & $\begin{array}{l}\text { I think it is more important that my clothes are comfortable than whether they } \\
\text { look good on me. }\end{array}$ & .76 & \multirow{4}{*}{$\begin{array}{c}19.35 \\
(43.91)\end{array}$} & \multirow{4}{*}{.72} & \multirow{4}{*}{3.06} \\
\hline & I think more about how my body feels than how my body looks*. & .73 & & & \\
\hline & I rarely think about how I look*. & .71 & & & \\
\hline & I rarely compare how I look with how other people look*. & .69 & & & \\
\hline \multirow{4}{*}{$\begin{array}{r}\text { Control } \\
\text { belief }\end{array}$} & I can weigh what I'm supposed to when I try hard enough. & .74 & \multirow{4}{*}{$\begin{array}{c}14.24 \\
(58.15)\end{array}$} & \multirow{4}{*}{.61} & \multirow{4}{*}{3.72} \\
\hline & $\begin{array}{l}\text { I think a person can look pretty much how they want to if they are willing to } \\
\text { work at it. }\end{array}$ & .67 & & & \\
\hline & I think a person is pretty much stuck with the looks they are born with*. & .65 & & & \\
\hline & I think a person's weight is mostly determined by the genes they are born with*. & .57 & & & \\
\hline
\end{tabular}

* Reverse score item.

〈Table 3〉 The consumer groups by objectified body consciousness

\begin{tabular}{l|c|c|c}
\hline $\begin{array}{l}\text { Consumer groups } \\
\text { Factors }\end{array}$ & $\begin{array}{c}\text { Objectified } \\
\text { group }(\mathrm{n}=280)\end{array}$ & $\begin{array}{c}\text { Non objectified } \\
\text { group }(\mathrm{n}=368)\end{array}$ & $F$ \\
\hline Body shame & 3.65 & 2.65 & $861.70^{* * *}$ \\
\hline Body surveillance & 3.30 & 2.88 & $83.71^{* * *}$ \\
\hline Control belief & 3.85 & 3.62 & $28.05^{* * *}$ \\
\hline$* * * p<.001$ & \multicolumn{4}{|l}{}
\end{tabular}

러한 결과는 연령이 증가할수록 매스미디어를 통 해 제시되는 외모에 대한 사회문화적 환경의 영향 에 더 오래 그리고 지속적으로 노출됨으로써 현대 사회의 이상적인 미적기준을 내면화하는 경향이 증 가하기 때문으로 판단된다(Lee, 2013).

객체화 신체의식에 따라 성인 남성 소비자를 유 형화하기 위하여 군집의 수를 2 6개로 지정하여 $\mathrm{K}-$ means 군집분석을 실시하였다. 2 6개 군집에 대한 각 군집분석에서 나타난 변량분석표, 객체화 신체 의식 3 하위 차원의 점수와 각 군집에 따른 피험자 의 인구통계학적 특성에서의 차이를 고려한 결과, 성인 남성을 2 개 군집으로 분류하였을 때가 가장
세분시장의 특징이 명확하고, 인구통계학적 특성에 서도 뚜렷한 차이를 지니는 것으로 나타나 타당하 다고 판단되었다. 따라서 본 연구에서는 성인 남성을 신체수치심과 신체감시성이 높은 객체화 유형 $(\mathrm{n}=280)$ 과 신체수치심과 신체감시성이 낮은 비객체화 유형 $(n=368)$ 으로 분류하였다. 변량분석 결과를 살펴보 면, 신체수치심, 신체감시성, 통제신념 3요인 모두 에서 집단 간 유의한 차이가 있었으며, $F$ 값을 고려 해볼 때 집단구분에 가장 영향력 있는 변인은 신체 수치심으로 나타났다. 이러한 결과는 신체수치심이 신체감시차원보다 더 중요한 영향력을 미친다는 Jeon and Chung(2011)의 연구결과를 지지한다. 통제 신념에서도 객체화 유형이 비객체화 유형보다 통계 적으로 유의하게 높긴 하였으나, 평균점수를 살펴보 면 모두 중간 이상으로 나타나, 집단구분에 따른 큰 의미는 없다고 판단된다. 이러한 결과는 신체수치 심과 신체감시성은 유의한 상관관계를 지니는 반면, 통제신념은 신체수치심과 신체감시성과는 다른 개 념으로서 외모관련행동의 발생에 영향을 주는 일종 의 동기적 역능감으로 판단된다고 한 선행연구 $(\mathrm{Gim}$ et al., 2007)의 내용과 같은 맥락이라고 할 수 있다. 
$\langle$ Table 4〉 Demographic characteristics by objectified body consciousness groups

\begin{tabular}{|c|c|c|c|c|}
\hline \multicolumn{2}{|c|}{ Demographic characteristics } & $\begin{array}{l}\text { Objectified group } \\
\qquad(\mathrm{n}=280)\end{array}$ & $\begin{array}{c}\text { Non objectified group } \\
(\mathrm{n}=368)\end{array}$ & $\chi^{2}$ \\
\hline \multirow{4}{*}{$\begin{array}{l}\text { Age } \\
\text { group }\end{array}$} & 20 29 years old & $85(30.4)$ & $73(19.8)$ & \multirow{4}{*}{$14.64 * * *$} \\
\hline & 30 39 years old & $75(26.8)$ & $86(23.4)$ & \\
\hline & $40-49$ years old & $64(22.9)$ & $102(27.7)$ & \\
\hline & $50 \sim 59$ years old & $56(20.0)$ & $107(29.1)$ & \\
\hline \multirow{7}{*}{$\begin{array}{l}\text { Type of } \\
\text { occupation }\end{array}$} & Students & $57(21.1)$ & $41(11.5)$ & \multirow{7}{*}{$20.48^{* *}$} \\
\hline & Office work & $121(44.8)$ & $143(40.2)$ & \\
\hline & Specialized work & $14(5.2)$ & $20(5.6)$ & \\
\hline & Management/administrative work & $24(8.9)$ & $40(11.2)$ & \\
\hline & Sales/service work & $22(8.1)$ & $55(15.4)$ & \\
\hline & Production/technical work & $27(10.0)$ & $42(11.8)$ & \\
\hline & Inoccupation & $5(1.9)$ & $15(4.2)$ & \\
\hline \multirow{4}{*}{$\begin{array}{l}\text { Pocket mony } \\
\text { per a month }\end{array}$} & Less than 200,000 won & $51(18.2)$ & $91(24.7)$ & \multirow{4}{*}{$23.91 * * *$} \\
\hline & 200,000 less than 400,000 won & $105(37.5)$ & $181(49.2)$ & \\
\hline & 400,000 less than 600,000 won & $53(18.9)$ & $37(10.1)$ & \\
\hline & Over 600,000 won & $71(25.4)$ & $59(16.0)$ & \\
\hline
\end{tabular}

$* * p<.01, * * * p<.001$

성인 남성의 객체화 신체의식 유형에 따라 인구 통계학적 특성에 어떠한 차이가 있는지를 알아보 기 위해 $\chi^{2}$ 검정을 실시한 결과, 피험자의 연령, 직 업, 한 달 용돈에서 통계적으로 유의한 차이가 나 타났다. 분석 결과를 살펴보면, 객체화 유형은 20 30 대 연령층의 비중이 높은 반면, 비객체화 유형은 40 50대 연령층의 비중이 상대적으로 높은 것으로 나타났다. 직업에서는 객체화 유형은 학생과 사무 직 종사자의 비중이 높은 반면, 비객체화 유형은 영업/서비스직과 관리직의 비중이 높게 나타났다. 한 달 용돈에서는 객체화 유형은 한 달 용돈이 40 만 원 이상으로 비교적 용돈이 많은 집단의 비중이 높은 반면, 비객체화 유형은 비교적 용돈이 적은 집단의 비중이 높게 나타났다. 이러한 결과를 정리 해 보면 객체화 유형은 20 30대의 청년층, 학생과 사무직 종사자, 한 달 용돈이 많은 집단의 비중이 높은 반면, 비객체화 유형은 40 50대의 중년층, 영 업/서비스직과 관리직 종사자, 한 달 용돈이 적은 집단의 비중이 높음을 알 수 있다.

\section{Appearance management behavior}

성인 남성의 외모관리행동을 알아보기 위해 외 모관리 동기, 정보원활용, 외모관리비용, 외모관리 경험, 외모관리의 필요성과 수행의도를 조사한 결 과는 〈Table 5$\rangle$ 와 같다.

성인 남성의 외모관리 동기로는 개성표현이나 매력증진 등의 자기만족이 절반 이상으로 제시되 어 가장 중요한 동기였으며, 그 외에 주변사람들의 시선 때문에, 성공적인 취업이나 직장생활을 위해, 이성에게 호감을 주기 위해서의 순으로 제시되었 다. 이러한 결과는 남성의 외모관리행동에서 자기 만족이 가장 중요한 동기로 제시된 선행연구(Jung \& Lee, 2011; Woo, 2005) 결과를 지지한다.

한편 사람들은 일반적으로 외모관리를 위한 정 보원을 하나 이상 활용하는 경우가 많으므로, 외모 관리를 위해 사용하는 정보원을 하나 이상 응답할 수 있도록 하여 다중응답분석을 실시하였다. 그 결 과, 피험자의 약 $75.3 \%$ 가 인터넷을 외모관리를 위 해 중요하게 고려하는 정보원이라고 응답하여 성 인 남성의 가장 중요한 정보원은 인터넷인 것으로 나타났으며, TV와 친구 및 주변사람도 주요 정보 원으로 제시되었다. 그러나 여성과 달리 남성은 외 
$\langle$ Table 5〉 Male adult' appearance management behavior

$(n=648)$

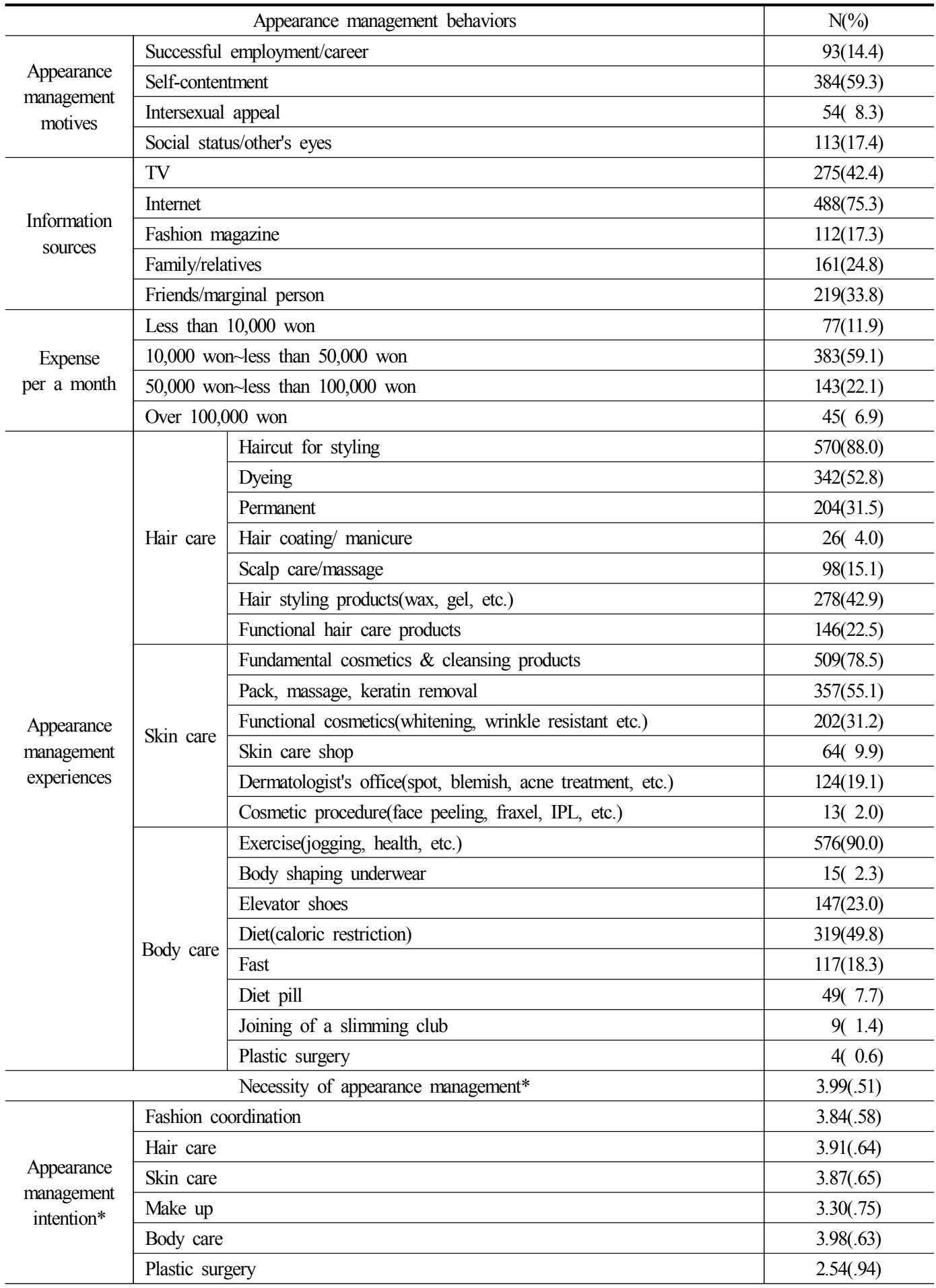

* This variable presented mean value and standard deviation. 
모관리를 위한 정보원으로 패션잡지를 활용하는 정도는 상대적으로 낮게 나타났다. 이러한 결과는 남성들은 익명성이 보장되는 인터넷을 중요한 정 보원천으로 활용하며, 패션잡지 구독률은 낮게 나 타난 선행연구(Ku et al., 2010)의 결과와 일치한다.

성인 남성의 한 달 외모관리비용으로는 $1 \sim 5$ 만 원 미만이 절반 이상으로 가장 일반적이었고, 그 다 음으로는 5 10만 원 미만이었으며, 10 만 원 이상을 사용하는 경우는 소수에 불과한 것으로 나타났다.

성인 남성이 수행해본 외모관리방법을 헤어관리, 피부관리, 체형관리의 측면에서 조사하였다. 헤어 관리에서는 성인 남성의 대부분(88.0\%)이 스타일 을 위한 커트를 하는 것으로 나타나 가장 일반적이 었고, 약 절반 정도가 염색과 왁스나 젤 등의 헤어 스타일링 제품을 사용하고 있었으며, 그 외에 퍼머, 기능성 헤어제품의 사용, 두피관리 및 마사지의 순으 로 나타났다. 피부관리방법으로는 성인 남성의 $78.5 \%$ 가 스킨, 로션 등의 기초화장품과 세안용 제품을 사용하였으며, 팩/마사지/각질제거도 절반 이상의 소비자가 수행하는 것으로 나타났고, 그 외에 미백, 주름방지, 탄력개선 등을 위한 기능성 화장품과 점, 잡티, 여드름 개선 등을 위한 피부과 방문의 순으 로 피부관리를 수행하였으나, 전문 피부관리실이나 박피, 프락셀, 아이피엘 등의 피부시술을 수행하는 경우는 소수에 불과하였다. 체형관리방법으로는 $90 \%$ 의 성인 남성이 조깅, 헬스 등의 운동을, 약 절반 정 도가 소식이나 칼로리 제한 등의 일상적인 다이어 트를 수행하여 운동과 다이어트가 성인 남성의 가 장 일반적인 체형관리방법으로 제시된 반면, 몸매 보정속옷, 체형관리실 이용, 성형수술 등의 방법을 수행하는 경우는 매우 극소수에 해당하였다.

외모관리의 필요성을 조사한 결과, 평균이 3.99(1 5점 범위)로 나타나, 성인 남성도 외모관리의 필요 성을 매우 높게 인식하고 있는 것으로 나타났다. 외모관리방법에 대한 수행의도를 살펴보면, 체형관 리에 대한 수행의도가 가장 높았으며, 헤어관리, 피 부관리, 의복관리도 높은 수행의도를 보였고, 메이 크업에 대한 수행의도도 중간 이상이었으나, 성형 을 통한 외모개선은 중간 이하로 수행의도가 낮았 다. 이러한 결과는 성인 남성들은 외모관리행동 중 체형관리를 가장 중요하게 고려한다고 한 선행연
구(Kim \& Park, 2010; Park \& Park, 2008; Woo, $2005)$ 결과와 20 50대 남성의 외모관리행동을 조 사한 결과, 외모개선이나 성형 등의 적극적인 외모 관리행동에는 보수적인 태도를 보였다는 $\mathrm{Ku}$ et al. (2010)의 결과와 일치하는 것으로 보인다.

\section{Appearance management behavior by objectified} body consciousness

성인 남성의 객체화 신체의식 유형에 따라 외모 관리행동에 어떠한 차이가 있는지를 알아보기 위 해 외모관리 동기와 외모관리 비용에 대해서는 $\chi^{2}$ 검증을 실시하였고, 다중응답분석은 $\chi^{2}$ 검증을 실 시하는 것이 통계적으로 타당하지 않으므로 외모 관리정보원과 외모관리경험에 대해서는 교차분석을, 외모관리의 필요성과 수행의도에 대해서는 $t$-test를 실시하였으며, 그 결과는 〈Table 6〉과 같다.

성인 남성의 외모관리 동기는 객체화 신체의식 유형에 따라 통계적으로 유의한 차이가 나타나지 않았으며, 객체화 유형과 비객체화 유형 모두 개성 표현이나 매력증진 등의 자기만족이 가장 중요한 동기로 나타났다.

외모관리 정보원에서는 객체화 유형 $(\mathrm{n}=280$, 전 체응답빈도수 $=600)$ 은 1 인당 평균 2 3개의 정보원 을 활용하고 있는 반면, 비객체화 유형 $(\mathrm{n}=368$, 전체 응답빈도수 $=655)$ 은 1 인당 평균 1 개의 정보원을 활용하고 있는 것으로 나타나, 객체화 유형이 비객 체화 유형보다 외모관리를 위해 더 다양한 정보원 을 활용하고 있음을 알 수 있었다. 분석결과를 살 펴보면, 객체화 유형과 비객체화 유형 모두 인터넷 이 가장 중요한 정보원이었으나, 패션잡지의 경우 는 객체화 유형(23.9\%)이 비객체화 유형(12.2\%)보 다 2 배 정도 높은 활용도를 보였으며, TV의 경우도 객체화 유형(47.9\%)이 비객체화 유형(38.3\%)보다 높은 활용도를 나타냈다. 따라서 객체화 유형은 비 객체화 유형보다 외모관리를 위해 더 다양한 정보 원을 사용하며, 특히 패션잡지와 $\mathrm{TV}$ 의 활용도가 상대적으로 높음을 알 수 있었다.

외모관리 비용은 객체화 신체의식 유형에 따라 유의한 차이가 나타났다 $\left(\chi^{2}=35.79^{* * *}\right)$. 객체화 유 형과 비객체화 유형 모두 한 달 외모관리비용으로 $1 \sim 5$ 만 원 미만을 사용하는 것이 일반적이었으나, 5 
$\langle$ Table 6〉 Differences between by objectified and non-objectified groups in appearance management behavior $(\mathrm{n}=648)$

\begin{tabular}{|c|c|c|c|c|c|}
\hline & \multirow{2}{*}{\multicolumn{2}{|c|}{ Appearance management behaviors }} & $\begin{array}{l}\text { Objectified } \\
\text { group }\end{array}$ & $\begin{array}{c}\text { Non objectified } \\
\text { group }\end{array}$ & \multirow[t]{2}{*}{$\chi^{2}$} \\
\hline & & & $\mathrm{N}(\%)$ & $\mathrm{N}(\%)$ & \\
\hline \multirow{4}{*}{$\begin{array}{c}\text { Appearance } \\
\text { management } \\
\text { motives }\end{array}$} & \multicolumn{2}{|c|}{ Successful employment/career } & $46(16.4)$ & $47(12.8)$ & \multirow{4}{*}{2.39} \\
\hline & \multicolumn{2}{|c|}{ Self-contentment } & $160(57.1)$ & $224(60.9)$ & \\
\hline & \multicolumn{2}{|c|}{ Intersexual appeal } & $26(9.3)$ & $28(7.6)$ & \\
\hline & \multicolumn{2}{|c|}{ Social status/other's eyes } & $48(17.1)$ & $65(17.7)$ & \\
\hline \multirow{5}{*}{$\begin{array}{c}\text { Information } \\
\text { sources }\end{array}$} & \multicolumn{2}{|l|}{ TV } & $134(47.9)$ & $141(38.3)$ & \multirow{5}{*}{$\begin{array}{c}\text { Multiple } \\
\text { response } \\
\text { analysis }\end{array}$} \\
\hline & \multicolumn{2}{|c|}{ Internet } & $222(79.3)$ & $266(72.3)$ & \\
\hline & \multicolumn{2}{|c|}{ Fashion magazine } & $67(23.9)$ & $45(12.2)$ & \\
\hline & \multicolumn{2}{|c|}{ Family/relatives } & $72(25.7)$ & $89(24.2)$ & \\
\hline & \multicolumn{2}{|c|}{ Friends/marginal person } & $105(37.5)$ & $114(31.0)$ & \\
\hline \multirow{4}{*}{$\begin{array}{c}\text { Expense } \\
\text { per a month }\end{array}$} & \multicolumn{2}{|c|}{ Less than 10,000 won } & $22(7.9)$ & $55(14.9)$ & \multirow{4}{*}{$35.79 * * *$} \\
\hline & \multicolumn{2}{|c|}{10,000 less than 50,000 won } & $144(51.4)$ & $239(64.9)$ & \\
\hline & \multicolumn{2}{|c|}{50,000 less than 100,000 won } & $84(30.0)$ & $59(16.0)$ & \\
\hline & \multicolumn{2}{|c|}{ Over 100,000 won } & $30(10.7)$ & $15(4.1)$ & \\
\hline \multirow{21}{*}{$\begin{array}{l}\text { Appearance } \\
\text { management } \\
\text { experiences }\end{array}$} & \multirow{7}{*}{$\begin{array}{l}\text { Hair } \\
\text { care }\end{array}$} & Haircut for styling & $252(90.0)$ & $318(86.4)$ & \multirow{7}{*}{$\begin{array}{l}\text { Multiple } \\
\text { response } \\
\text { analysis }\end{array}$} \\
\hline & & Dyeing & $155(55.4)$ & $187(50.8)$ & \\
\hline & & Permanent & $108(38.6)$ & $96(26.1)$ & \\
\hline & & Hair coating/ manicure & $12(4.3)$ & $14(3.8)$ & \\
\hline & & Scalp care/massage & $55(19.6)$ & $43(11.7)$ & \\
\hline & & Hair styling products & $149(53.2)$ & $129(35.1)$ & \\
\hline & & Functional hair care products & $82(29.3)$ & $64(17.4)$ & \\
\hline & \multirow{6}{*}{$\begin{array}{l}\text { Skin } \\
\text { care }\end{array}$} & Fundamental cosmetics & $211(75.4)$ & $298(81.0)$ & \\
\hline & & Pack, massage, keratin removal & $177(63.2)$ & $180(48.9)$ & \\
\hline & & Functional cosmetics & $104(37.1)$ & $98(26.6)$ & Multiple \\
\hline & & Skin care shop & $34(12.1)$ & $30(8.2)$ & analysis \\
\hline & & Dermatologist's office & $67(23.9)$ & $57(15.5)$ & \\
\hline & & Cosmetic procedure & $8(2.9)$ & $5(1.4)$ & \\
\hline & & Exercise(jogging, health, etc.) & $254(91.4)$ & $322(89.0)$ & \\
\hline & & Body shaping underwear & $12(4.3)$ & $3(0.8)$ & \\
\hline & & Elevator shoes & $79(28.4)$ & $68(18.8)$ & \\
\hline & Body & Diet(caloric restriction) & $167(60.1)$ & $152(42.0)$ & Multiple \\
\hline & care & Fast & $63(22.7)$ & $54(14.9)$ & \\
\hline & & Diet pill & $29(10.4)$ & $20(5.5)$ & \\
\hline & & Joining of a slimming club & $5(1.8)$ & $4(1.1)$ & \\
\hline & & Plastic surgery & $3(1.1)$ & $1(0.3)$ & \\
\hline & Necess & of appearance management* & $4.17(.49)$ & $3.85(.48)$ & $8.28 * * *$ \\
\hline & Fashic & coordination & $4.01(.65)$ & $3.71(.60)$ & $7.00 * * *$ \\
\hline & Hair & & $4.12(.55)$ & $3.75(.66)$ & $7.68 * * *$ \\
\hline Appearance & Skin & & $4.09(.63)$ & $3.71(.61)$ & 7.80 *** \\
\hline intention* & Make & & $3.51(.75)$ & $3.15(.71)$ & $6.15^{* * *}$ \\
\hline & Body & & $4.19(.57)$ & $3.82(.63)$ & $7.77 * * *$ \\
\hline & Plastic & argery & $2.74(.95)$ & $2.40(.90)$ & $4.67 * * *$ \\
\hline
\end{tabular}

* This variable presented mean value and standard deviation. $* * * p<.001$ 
만 원 이상 사용한다는 응답은 객체화 유형 $(40.7 \%)$ 이 비객체화 유형(20.1\%)보다 약 2 배 정도 많은 반 면 1만 원 미만을 사용한다는 응답은 객체화 유형 (7.9\%)이 비객체화 유형 $(14.9 \%)$ 보다 약 2 배 정도 적 어, 객체화 유형이 비객체화 유형보다 외모관리를 위 해 더 많은 비용을 사용하고 있는 것으로 나타났다.

객체화 신체의식 유형에 따라 성인 남성이 수행 해본 외모관리방법을 헤어관리, 피부관리, 체형관 리로 구분하여 살펴본 결과, 모든 외모관리방법에 서 객체화 유형이 비객체화 유형보다 외모관리행 동을 더 많이 수행한 것으로 나타났다. 헤어관리에 서는 헤어스타일링 제품, 기능성 헤어관리제품, 퍼 머 등의 방법에서 유형 간에 상대적으로 많은 차이 가 나타났으며, 피부관리에서는 팩/마사지/각질제 거와 미백, 미백, 주름방지 등의 기능성화장품 사용 에서 많은 차이를 보였고, 체형관리에서는 다이어 트 제품과 몸매보정 속옷의 사용에서 객체화 유형 이 비객체화 유형보다 약 2 배 정도 많이 수행한 것 으로 나타났다.

외모관리의 필요성과 수행의도에서도 객체화 신 체의식 유형 간에 통계적으로 유의한 차이가 있어, 객체화 유형이 비객체화 유형보다 외모관리의 필 요성과 수행의도가 더 높게 나타났다. 두 유형 모 두에서 가장 수행의도가 높은 것은 체형관리였고, 그 다음이 헤어관리였으나, 객체화 유형은 패션연 출보다 피부관리의 수행의도가 높게 나타난 반면, 비객체화 유형은 패션연출과 피부관리의 수행의도 가 동일하게 나타나, 객체화 유형이 비객체화 유형 보다 피부관리의 수행의도가 상대적으로 높았다. 한편, 성형을 통한 외모개선에서도 객체화 유형이 비객체화 유형보다 수행의도가 높긴 하였으나, 평 균점수를 고려해볼 때 두 유형 모두 수행의도가 중 간 이하로 낮게 나타났다.

\section{Conclusion and Suggestion}

본 연구는 성인 남성의 객체화 신체의식과 외모 관리행동을 알아보고, 객체화 신체의식에 따른 외 모관리행동의 차이를 조사하였으며, 본 연구결과를 통한 결론은 다음과 같다.

첫째, 성인 남성의 객체화 신체의식을 조사한 결
과, 신체수치심과 신체감시성은 중간 수준이나 통 제신념은 높게 나타나, 남성들은 여성에 비해 상대 적으로 외모에 대한 사회문화적 영향을 덜 받으며, 자신의 노력에 따라 외모를 변화시킬 수 있다는 신 념은 강한 것으로 보여진다. 그러나 청소년을 대상 으로 한 선행연구(Lim, 2010) 결과와 비교해 보면 성인 남성을 대상으로 수행된 본 연구결과에서는 연령 증가와 함께 남성의 신체수치심이 크게 증가 하는 것으로 나타났으므로, 연령에 따른 객체화 신 체의식의 변화 경향과 이에 영향을 미치는 선행요 인이 무엇인지를 파악할 필요가 있다고 판단된다.

둘째, 객체화 신체의식에 따라 성인 남성 소비자 를 세분화하는데 있어 가장 중요한 영향력을 미친 변인은 신체수치심이었고, 통제신념에서는 두 유형 간에 큰 차이가 보이지 않았다. 또한 2 6개의 군집 을 지정하여 군집분석을 실시한 결과에서도 통제 신념은 신체수치심이나 신체감시성과는 달리 집단 구분에 의미 있는 특징이 발견되지 않았다. 따라서 신체수치심은 객체화 신체의식을 설명하는데 가장 중요한 영향력을 미치는 변인인 반면, 통제신념은 기 존 선행연구(Gim et al., 2007; Jeon \& Chung, 2011) 에서 제안한 것처럼 객체화 신체의식의 하위척도 라기 보다는 다른 차원의 개념으로 이해하는 것이 바람직할 것으로 보여진다.

셋째, 성인 남성의 외모관리행동을 살펴보면 자 기만족이 가장 중요한 동기였으며, 정보원으로는 인터넷이 매우 중요한 위치를 차지하고, TV, 친구 와 주변사람도 주요 정보원으로 사용되나, 패션잡 지의 활용도는 상대적으로 낮았다. 따라서 성인 남 성을 고객으로 하는 업체에서는 인터넷이나 모바 일 등을 통한 소비자와의 커뮤니케이션 방법을 개 발하는 것이 효과적일 것으로 판단된다. 성인 남성 의 외모관리의 필요성과 수행의도는 높은 수준으로 나타났는데, 특히 체형관리에 대한 수행의도가 가 장 높았고, 헤어, 피부, 메이크업 등의 다양한 외모 관리행동에서도 과거에 비해 적극적인 태도를 보 였다. 이러한 경향을 살펴볼 때 남성 외모관련시장 은 앞으로 지속적인 성장세를 보일 것으로 예측되 므로, 시장의 변화에 부응하기 위하여 관련기업에 서는 소비자의 욕구를 만족시킬 수 있는 다양한 상 품과 서비스의 개발이 이루어져야 하리라 생각된다. 
넷째, 본 연구결과, 성인 남성의 외모관리행동은 객체화 신체의식 유형에 따라 많은 차이가 있는 것 으로 나타나, 객체화 신체의식은 여성뿐 아니라, 남 성의 외모관리행동에 영향을 미치는 주요한 변인 임을 확인할 수 있었다. 한편, 신체수치심과 신체감 시성이 높은 객체화 유형은 외모관리행동에 매우 적극적인 태도를 보이고, 비교적 많은 비용을 사용 하며, 앞으로의 외모관리 수행의도도 높게 나타나, 기업입장에서 볼 때 시장매력도가 높은 주요 소비 자집단으로 제시되었으므로, 이들의 소비자특성과 라이프스타일 및 구매행동을 보다 구체적으로 이 해하기 위한 노력이 필요할 것으로 판단된다.

본 연구는 외모관리행동에 주요한 영향을 미칠 것으로 예측되는 객체화 신체의식을 독립변인으로 하위차원을 파악하고, 성인 남성의 객체화 신체의 식 수준을 알아봄으로써 외모지상주의 가치관이 팽배한 한국의 사회문화적 환경이 성인 남성에게 미치는 영향을 파악하는데 도움을 줄 수 있다고 판 단되며, 나아가 지나치게 외모를 중시하는 사회문 화적 영향의 문제점을 개선하고, 자아존중감을 높 이기 위한 교육 프로그램을 개발하는데도 도움이 되리라 여겨진다. 또한 본 연구는 외모관련 산업에 서 주요 소비계층으로 새롭게 부각되고 있는 성인 남성 소비자를 세분화하고, 세분집단의 특성을 파 악하였으며, 외모관리행동을 구매동기, 정보원 활 용, 구매비용, 다양한 외모관리경험과 수행의도 등 외모관리구매행동을 포함한 다양한 측면에서 조사 하였으므로, 본 연구결과는 남성을 대상으로 하는 외모관련 산업체에게 남성 소비자의 특성을 보다 구체적으로 이해하고, 이에 따른 상품개발과 마케 팅 전략을 수립하는데 도움을 줄 수 있을 것으로 기대된다.

본 연구는 서울, 경기지역과 대전, 충남지역에 거주하는 성인 남성을 대상으로 편의표집방법에 의해 피험자를 선정하였으므로 연구결과를 일반화 하기에는 주의가 필요하다. 본 연구에서 객체화 신 체의식에 대한 요인분석 결과, 통제신념의 신뢰도 계수와 객체화 신체의식에 대한 설명력을 나타내 는 총 변량이 상대적으로 낮게 제시된 점, 그리고 군집분석 결과 소비자가 다양하게 유형화되지 못 한 점 등은 연구의 제한점이라고 할 수 있다. 이러
한 결과는 통제신념이 외모관련행동의 발생에 영 향을 주는 일종의 동기적 역능감으로 신체수치심 이나 신체감시성과 유의한 상관관계를 지니지 않 는 다른 개념으로 판단되므로, 객체화 신체의식 하 위척도로 적절하지 못하다고 제시한 선행연구(Gim et al., 2007) 결과를 고려해볼 때, 통제신념이 오히 려 객체화 신체의식에 대한 총 설명력을 감소시키 는 원인으로 작용하였을 가능성이 있다고 판단된 다. 또한 통제신념은 군집분석에서도 세분집단에 따른 일관된 경향성이 없게 나타났다. 따라서 객체 화 신체의식 차원을 신체수치심과 신체감시성의 두 차원으로 구성하는 것이 적절할 것으로 여겨진다.

후속연구에 대한 제언으로는 첫째, 객체화 신체 의식에 대한 연구가 주로 여성을 대상으로 이루어 졌으며, 남성에 대한 연구는 아직 매우 소수에 불 과하므로, 남성의 객체화 신체의식과 그 영향 변인 이 무엇인지를 파악하기 위한 연구가 수행되어야 할 것으로 판단되며, 성별이나 연령에 따라 객체화 신체의식에 어떠한 차이가 있는지도 알아볼 필요 가 있다고 생각된다. 둘째, 본 연구에서는 성인 남 성의 객체화 신체의식과 외모관리행동에 대하여 조사하였는데, 성인 남성의 외모관리행동에 영향을 미칠 것으로 사료되는 보다 다양한 선행변인들을 대상으로 그 상대적 영향력을 파악한다면 남성의 외모관리행동을 보다 포괄적으로 이해하고 예측하 는데 유용하리라 여겨진다.

\section{References}

An, N. Y.(2007). The effects of sociocultural attitudes toward appearance and objectified body consciousness on appearance-management behaviors. Unpublished master's thesis, Chonnam National University, Gwangju, Korea.

Calogero, R. M., Davis, W. N., \& Thompson, J. K. (2005). The role of self-objectification in the experience of women with eating disorders. Sex Roles, 53(1-2), 43-50.

Fredrickson, B. L., \& Roberts, T. A. (1997). Objectification theory: toward understanding women's lived experiences and mental health risks. Psy- 
chology of Women Quarterly, 21(2), 173-206.

Gim, W. S., Park, E. A., \& Timothy, T. (2009).

Objectified body consciousness, body-esteem and self-construals in East Asian women; a crossnational study on Korean, Chinese, and Japanese college students. The Korean Journal of Woman Psychology, 14(1), 23-46.

Gim, W. S., Ryu, Y. J., \& Park, E. A.(2007). The Korean version of objectified body consciousness scales(K-OBCS): development and validation. Korean Journal of Psychology, 26(2), 329-349.

Ha, J. K.(2009). Clothing and make-up behavior by appearance management motive. Korean Journal of Community Living Science, 20(30), 385-396.

Jeon, H. J., \& Chung, M. S.(2011). The influences of objectified body consciousness and body esteem on weight and hair management behavior. The Research Journal of the Costume Culture, 19(6), 1272-1287.

Jeon, J. H., \& Yoo, T. S.(2011). Directional relationships of public self-consciousness and sociocultural attitudes toward appearance and objectified body consciousness on image management behavior. Journal of the Korean Society of Clothing and Textiles, 35(11), 1333-1345.

Jung, H. J., \& Lee, Y.(2011). The expected values of appearance management of $20 \mathrm{~s}-30 \mathrm{~s}$ and $40 \mathrm{~s}-50 \mathrm{~s}$ male consumers on their men's suit buying behaviors. Journal of the Korean Society of Clothing and Textiles, 35(2), 125-135.

Kaiser, S. B.(1990). The social psychology of clothing: symbolic appearance in context (2nd ed.). New York: Macmillan.

Kim, C. H.(2011). A study on appearance concern and appearance management behavior by type of men's fashion lifestyle. Unpublished master's thesis, Kyungsung University, Busan, Korea.

Kim, M. J., \& Park, H. R.(2010). Appearance management typology \& the related factors in $20-30$ 's male consumer. Journal of Science, 36, 105-122.

Kim, Y.(2007). The effects of sociocultural pressure, internalization ideal beauty stereotype, objectified body consciousness on body satisfaction and appearance management behavior. Unpublished doctoral dissertation, Sung Kyun Kwan University, Seoul, Korea.

Kretchmar, J. L.(2001). Objectified body consciousness in african American and Caucasian college-age women of varying physical activity levels. Unpublished doctoral dissertation, The University of North Carolina at Chapel Hill, North Carolina, USA.

Ku, Y. S., Lee, Y. J., \& Choo, T. G.(2010). A study on appearance management behavior of male consumers( I ) -focusing on the age-. Journal of Korean Society of Clothing Industry, 12(4), 459466.

Ku, Y. S., Lee, Y. J., \& Choo, T. G.(2011). A study on appearance management behavior of male consumers(II). Journal of Korean Society of Clothing Industry, 13(1), 91-99.

Lee, M. S.(2013). A study on adolescents'body esteem and clothing behaviors according to the sociocultural attitude toward appearance. Journal of the Korean Fashion \& Costume Design Association, 15(2), 43-56.

Lee, S. H.(2012). Influence of fashion lifestyle factor of $30 \mathrm{~s}$ and $40 \mathrm{~s}$ male on their appearance management behavior. Unpublished master's thesis, Sung Kyun Kwan University, Seoul, Korea.

Lee, Y. J.(2007). Male consumers' motives of appearance management behavior. Journal of the Korean Society of Clothing and Textiles, 31(4), 551-562.

Lim, B. H.(2010). The effects of adolescences' sociocultural attitude toward appearance and objectified body-consciousness on appearance management behavior. Unpublished master's thesis, Daegu University, Daegu, Korea.

MaKinley, N. M., \& Hyde, J. S.(1996). The objectified body consciousness scale: development and validation. Psychology of Women Quarterly, 20, 
181-215.

McConnell, C. A.(2001). An object to herself: the relationship between girls and their bodies. Unpublished doctoral dissertation, University of Wisconsin, Madison, USA.

Morry, M. M., \& Staska, S. L.(2001). Magazine exposure: internalization, self-objectification, eating disorders, and body satisfaction in male and female university students. Canadian Journal of Behavioral Science, 33(4), 269-279.

Murnen, S. K.(2003). Thin, sexy women and strong, muscular men: grade-school children's responses to objectified images of women and men. Sex Roles, 49(9), 427-437.

No more uncle.(2013, December 17). The Korea Economic Daily. Retrieved December 17, 2013, from $\mathrm{http} / / /$ media.daum.net/news/wiew/print?news $\mathrm{Id}=20131217033404831$

Noll, S. M., \& Fredrickson, B. L.(1998). A mediational model linking self-objectification, body shame, and disordered eating. Psychology of Women Quarterly, 22(4), 623-636.

Park, H. W., \& Chung, M. S.(2011). The influence of appearance concern and body satisfaction on the appearance management behavior of male college students. The Research Journal of the Costume Culture, 19(5), 1119-1132.

Park, K. H., \& Yoo, H. S.(2012). An analysis of the causal relationships between cognition, attitude, and behavior toward appearance management. Journal of the Korean Home Economics Association,
50(1), 51-63.

Park, S. J., \& Park, K. S.(2008). Male attitude and recognition for appearance management behavior. The Research Journal of the Costume Culture, 16(3), 533-546.

Rapid growth of male tribe of value consciousness consumption.(2014, June 16). The Chosun Ilbo. Retrieved July 1, 2014, from http://blog.chusun. com/blog.log.print.screen:blogId $=51518 \& \log I d=$ 7441190

Ryou, E. J., \& Kim, Y. H.(2008). Appearance management behaviors and motives by body image of college men. Journal of the Korean Home Economics Association, 46(1), 63-72.

Spruce men $\cdots$ Yummy tribe'is increasing.(2014, June 2). SBS. Retrieved July 1, 2014, from http://www. sbs.co.kr/news/newsEndPagePrintPopup.do?news _id=N1002420505

Sung, Y. S., Park, E. A., Choi, K. Y., Kim, E. S., \& Lee, J. W.(2008). Male grooming: Beauty is power. 2008 Korean Psychological Association Annual Academic Conference Proceeding, 390-391.

Woo, J. Y.(2005). Metro-sexual trend and appearance control behavior by life-style of twenties-thirties men. Unpublished master's thesis, Kyung Hee University, Seoul, Korea.

Woo, S. J., \& Choi, K. H.(2011). Influence of male undergraduates'aesthetic consciousness upon appearance management behavior. Journal of the Korea Society of Cosmetology, 17(1), 185-195. 